\title{
God's Necessity on Anselmian Theistic Genuine Modal Realism
}

\author{
Matthew James Collier ${ }^{1}$
}

Published online: 31 July 2018

(C) The Author(s) 2018

\begin{abstract}
On Anselmian theism (AT), God is, amongst other things, a necessary being. On genuine modal realism (GMR), possible worlds are maximal mereological sums of spatiotemporally connected individuals. I argue in this paper that AT and GMR are either incompatible or their conjunction leads to - amongst other things - modal collapse. Specifically, I argue: regardless of whether God is concrete or abstract, His necessary existence either is inconsistent with AT-GMR or it leads to, amongst other things, modal collapse for AT-GMR. I conclude the paper by contending that, if I am correct, the ATist will have an argument against the truth of GMR, and the GMRist will have an argument against the truth of AT.
\end{abstract}

Keywords Genuine modal realism - Anselmian theism · Necessary being · Counterpart theory · Transworld identity

\section{Introduction}

Lewis's (1986) genuine modal realism (GMR) is the view that possible worlds are concrete entities, populated by concrete possibilia, which are alike in kind to our universe. Anselmian theism (AT) is the view that God is unitary, omnipotent, omniscient, omnibenevolent, simple (viz., He is without proper parts), a creator and sustainer of all that exists, and necessarily existent. Several authors believe AT and GMR to be compatible or at least their conjunction to be serviceable: indeed, Oppy $(1993,2009)$, Leftow (2012), Cameron (2009) and Almeida (2008, 2011, 2017) all think that GMR has the resources to accommodate the God of AT whilst remaining a (somewhat) fruitful theory. In this paper, I argue that the above authors are mistaken. Specifically, I argue: regardless of whether God is concrete or abstract, His necessary existence

Matthew James Collier

matthew.collier@oriel.ox.ac.uk

1 Oriel College, Oriel Square, University of Oxford, Oxford OX1 4EW, UK 
either is inconsistent with AT-GMR or it leads to, amongst other things, modal collapse for AT-GMR. ${ }^{1}$

The first section provides an exposition of GMR, and the remaining sections explore the ontological options for God on an AT-GMR framework. In my exploration of the ontological options for God on AT-GMR, I assess the recent contributions by Sheehy (2006, 2009), Davis (2008, 2009) and Vance (2016) and the work of their critics, Oppy (2009), Cameron (2009) and Almeida (2011, 2017), rebutting some of Sheehy, Davis and Vance's respective arguments, supporting others and making novel ones of my own. Here are the options: If God is concrete, then there are three ways to analyse God's necessity on AT-GMR: the first is through counterpart theory, which-I argueleads to AT-GMR's positing an infinite plurality of Gods and thereby being inconsistent; the second is through transworld identity, which-I argue-leads to, amongst other things, modal collapse; and the third is through taking God as the aggregate of all His counterparts, which - I argue - amongst other things, firstly leads to AT-GMR denying God's simplicity and thereby being inconsistent and secondly leads to modal collapse again. So, if God is concrete, then either AT-GMR is inconsistent or modal collapse ensues. If we construe God as abstract, then there is one option for analysing God's necessity: this is through taking God as existing from the standpoint of all worlds, which - I argue - leads to, amongst other things, the dilemma that either God is not causally efficacious or, again, modal collapse ensues. So, the general import of this paper is thus: whichever way we construe God's ontology on ATGMR, we either get inconsistency or, amongst other things, modal collapse.

If this result carries, the ATist may have good grounds to provide a new argument against GMR and the GMRist may have good grounds to provide a new argument against AT: indeed, if there are good arguments to support AT, and AT and GMR are incompatible or their conjunction is objectionable (through, amongst other things, modal collapse's being objectionable (to some at least)), then the ATist can employ these arguments to demonstrate the falsity of GMR; and, if there are good arguments to support GMR, and GMR and AT are incompatible or their conjunction is objectionable (through, amongst other things, modal collapse's being objectionable (to some at least)), then the GMRist can employ these arguments to demonstrate the falsity of AT.

\section{GMR}

Possible worlds are maximally inclusive, all-encompassing ways that a world might be, and theories concerning the ontological status of such worlds are numerous. ${ }^{2}$ Here, however, we are interested in only one type of possible worlds theory: GMR. So, what is the ontology of GMR-worlds? The principal ontological theses of GMR are thus: there exists an infinite plurality of possible worlds, where worlds are maximal mereological sums of spatiotemporally connected individuals, ontologically alike in kind to the world - the 'actual world' (hereafter '@')—-in which we reside, where such worlds fail to spatiotemporally and causally relate to worlds other than themselves, and

\footnotetext{
${ }^{1}$ For alternative objections and rebuttals, see Almeida $(2011,2017)$, Sheehy $(2006)$, Oppy $(1993,2009)$ and Davis $(2008,2009)$.

${ }^{2}$ For a good overview of different possible worlds theories, see Menzel (2016).
} 
whose parts, similarly, fail to spatiotemporally and causally relate to world-parts other than their own (worlds, thence, fail to overlap). So, for any individual, $x, x$ constitutes a world if and only if any of $x$ 's parts are, to each other, spatiotemporally connected, and any individual that is spatiotemporally connected to any of $x$ 's parts, constitutes one of $x$ 's parts. The spatiotemporal relation is thence transitive and symmetric, and if any two (or more) individuals are part of the same world, by being spatiotemporally connected, they are world-mates. All possible individuals, then, are confined to worlds, or are world-bound, insofar as they fail to exist in more than one world; if an individual is part of a world, it is part of that world only (this is Lewis's (1968: 111) 'nothing is in two worlds' principle). GMR-worlds, then, represent possibilities by being comprised of parts that instantiate certain qualitative features or properties. Moreover, applying the 'actual'-predicate to a world, $w$, or an individual, $x$, fails to ascribe a property to $w$ or $x$ that ontologically distinguishes it from other worlds or individuals; indeed, 'actual' and its cognates are indexical terms which depend upon the world in which the speaker resides. ${ }^{3}$

Now, to account for de re representation, GMR uses counterpart theory (CT). The counterpart relation is a resemblance relation such that, save holding reflexively, holds between distinct individuals that reside in distinct worlds, where such a relation respects individuals' intrinsic and extrinsic properties (and where such a relation need not be transitive nor symmetric). CT is used-and thus the doctrine of transworld identity ${ }^{4}$ is eschewed - to explain how worlds represent de re that a certain individual has a certain modal property; that is, CT provides an explanation of, and the truth-conditions for, the claim ' $x$ is possibly $F$ '. So, a world, $w$, represents de re that $x$ is possibly $F$ through $w$ 's having an individual-part, $y$, which has $F$, and which sufficiently resembles $x$ in the appropriate way (typically, that will mean that $y$ resembles $x$ more than any other individual in $w$ ). That is, $x$ 's being possibly $F$ is represented through an otherworldly counterpart of $x$ being $F^{5}$

So, to analyse de re modal predications, CT supplies the following biconditionals:

POSS-CT: $x$ is possibly $F \leftrightarrow$ a world, $w$, exists such that in $w, x$ has a counterpart (that may reside in another world, $u$ ) that is $F$.

NEC-CT: $x$ is necessarily $F \leftrightarrow$ in all worlds, $w$, all (relevant) counterparts of $x$ are $F$.

And so, GMR initially translates AT's necessity claim: 'God necessarily exists', through NEC, into the possible-worlds-discourse claim: 'in all worlds, it is true that God exists', and then into the language of CT: 'in all worlds, there exists a (relevant) counterpart of God that exists' ${ }^{6}$ Thus, to assess AT's necessity claim, we appeal to the biconditional:

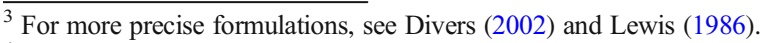

${ }^{4}$ Transworld identity is typically used by actualists: for example, see Plantinga (1974).

5 See Lewis (1986: ch.4) for a more precise exposition.

${ }^{6}$ This assumes both the concreteness of God and that CT is the correct way to analyse His necessary existence. Cameron (2009), in an attempt to rescue AT-GMR from objections which I later explore, suggests that ATGMRists could either reject CT or reject God as concrete. I later rebut Cameron's suggestions.
} 
NEC-G: God necessarily exists $\leftrightarrow$ in all worlds, $w$, there exists a (relevant) counterpart of God in $w$.

My question is, concerning God's necessary existence, are AT and GMR compatible and is their conjunction serviceable? I now defend the view that AT and GMR are either incompatible or their conjunction leads to, amongst other things, modal collapse.

\section{God's Ontology}

Lewis (1983: 39-40) provides three ontological categories for beings ${ }^{7}$ :

(A) Beings that exist wholly in a world, through being a world-part-i.e. possible individuals (e.g. persons, puddles, puppies...)

(B) Beings that exist partly in a world, through having world-parts that are wholly in worlds-i.e. cross-world individuals which are comprised of two or more (A)kind individuals which, in turn, wholly exist in worlds (e.g. the mereological summation of, say, puddle-counterparts)

(C) Beings that exist from a world's perspective, through being members of the most unrestricted domain that is considered, generally, suitable for evaluating the truth values of quantifications at worlds - i.e. non-individuals (e.g. pure sets...) ${ }^{8}$

Now, (A)- and (B)-kind individuals are concrete and (C)-kind individuals are abstract. So, which category must God fall under for AT-GMR to be consistent and serviceable? I argue that neither (A), (B) nor (C) are viable options.

\section{(A)-Kind-God}

Let us assume that God is (A)-kind. ${ }^{9}$ Recall: in assessing AT's claim that 'God necessarily exists', AT-GMRists appeal to the biconditional: (NEC-G) 'God necessarily exists $\leftrightarrow$ in all worlds, $w$, there exists a (relevant) God-counterpart'. So, we can ask: does construing God as (A)-kind, and analysing His necessity through CT, render ATGMR consistent and serviceable?

Almost every philosopher I have posed this question to has said that the answer is 'just obvious and unsurprising'. However, I have received two answer-types, each with roughly equal numbers of advocates: some say it is 'just obvious and unsurprising' that construing God as (A)-kind, and analysing His necessity through CT, renders AT-GMR inconsistent, and some say it is 'just obvious and unsurprising' that construing God as (A)-kind, and analysing His necessity through CT, renders AT-GMR consistent. $I$ think that construing God as (A)-kind, and analysing His necessity through CT, renders ATGMR inconsistent, and I argue for this below. Thus, if my response works, I shall deny

\footnotetext{
${ }^{7}$ I thank Vance (2016: 564) for highlighting Lewis's three categories for existence.

${ }^{8}$ Lewis considers (although, he remains agnostic) that if such things exist, universals would qualify for (C)kind membership.

${ }^{9}$ Predicating concreteness of God is commonplace: e.g. Plantinga (1985: 90) affirms: '[God] is the only concrete object that exists in every possible world'.
} 
the legitimacy of a view that appears 'just obvious and unsurprising' to some, and support a view that is 'just obvious and unsurprising' to others.

Now for the arguments. Given that individuals are world-bound and given NEC-G, God's necessary existence is not grounded in His existing in all worlds, ${ }^{10}$ but in the fact that God possesses a counterpart in all worlds. ${ }^{11}$ But, here, Sheehy (2006: 319-20) raises two objections to this analysis of (A)-kind-God's necessity on AT-GMR - the first objection is also briefly alluded to by Davis (2009: 440; 2008: 60). Firstly, if God necessarily exists, He cannot be the only, unique God; indeed, there must exist an infinite plurality of God-counterparts, where each God-counterpart is wholly bound to a single world. But, according to AT, there exists only one, unique God. Thus: in what sense can AT-GMRists uphold monotheism if God is (A)-kind and His necessity is analysed through CT ${ }^{12}$

There is, I believe, a plausible response here. Sheehy and Davis's objection seems a mere rejection of $\mathrm{CT}$ as an adequate account of de re necessity; there is nothing special about analysing God's modal properties on CT, as CT is inadequate, simpliciter. Sheehy and Davis's objection can be viewed as a Humphrey-style objection: viz., they use God as an example to (albeit unwittingly) insist that CT is unserviceable. ${ }^{13}$ Indeed, if having, say, a Bill-counterpart in $w$ is enough to make a de re possibility claim about Bill-and not the Bill-counterpart - true, then this apparatus should work for de re necessity claims of God; if only one Bill exists, yet Bill is possibly $F$ because otherworldly-Billlike individuals are $F$, why should it be different for God's necessary existence? Sheehy and Davis do not think it works for God, and so they should think that it should not work for anything else.

This response, I believe, miscarries. Yes, on CT, for Bill to be possibly $F$, there must exist otherworldly-Bill-like individuals (counterparts) who are $F$, and this does not seem to threaten Bill's uniqueness. But, there is nothing unique about Bill-like individuals - there can freely exist Bill-like individuals in other worlds. God, however, is different. For AT, a God-like individual is unique; there should exist, in all of reality (which, on GMR, is the total set of worlds), only one God-like individual. ${ }^{14}$ Yes, from the perspective of each world, there exists one God only, who necessarily exists due to the existence of otherworldly counterparts - so the necessary existence requirement is satisfied. But this, I argue, comes at the cost of violating the uniqueness requirement: if we- - so to speak - look down on logical space, we see a plurality of God-like individuals. Whilst it is permissible to see a plurality of Bill-like individuals - as there is no uniqueness requirement for Bill-like individuals - it is not permissible, on AT, to see a

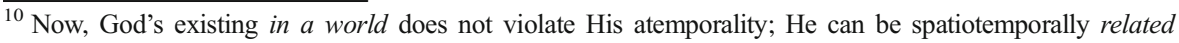
without His being temporal or spatial. But, if I am wrong here, all the worse for AT-GMRists who posit (A)kind-God.

${ }^{11}$ Oppy $(1993,2009)$ and Leftow (2012) support the consistency of AT-GMR when construing God as (A)kind and analysing His necessary existence through CT.

${ }^{12}$ Steinhart (2013) embraces ordinal polytheism, which he claims is motivated by GMR.

${ }^{13}$ For the Humphrey objection, see Kripke (1980).

${ }^{14}$ An anonymous reviewer notes that unglorified humans are God-like in some respects (e.g. humans have some power over and knowledge of certain things) and humans become more God-like after they are glorified (e.g. they lose the ability to $\sin$ ). These two points, the reviewer suggests, do not seem to threaten the uniqueness of God. However, to be a sufficiently God-like-individual, it is not enough that a human resembles God to some degree and in only some respects. For example, the attribute of being a creator and sustainer of all that exists is required to be a sufficiently God-like-individual. We see that no human could have this attribute.
} 
plurality of God-like individuals. So, Sheehy and Davis's objection is not, I argue, a mere insistence of CT's inadequacy; God-like individuals (for AT) have different uniqueness requirements to Bill-like individuals.

Now, one may demur here. One may claim that, on taking God as (A)-kind and analysing His necessary existence through CT, there is no inconsistency in AT-GMR, since both the following claims are true:

(1) God is unique: there actually exists only one God-like individual.

(2) God necessarily exists and is necessarily unique: there exists only one counterpart of God in every world.

Certainly, the claims of AT ought to be translated into the language of GMR which, here, the AT-GMRist has chosen the language of CT-and once they are so translated, we see that the apparent incompatibility between AT and GMR disappears: both (1) and (2) remain true when we analyse (A)-kind-God's necessary existence through $\mathrm{CT} .^{15}$

This response, I believe, fails. Firstly, whilst it is true that AT-GMRists ought to translate their AT-claims into the language of GMR, it is not true that this requires ATGMRists to translate their AT-claims into the language of CT. Indeed, as we will see below, Cameron (2009) notes that Lewis suggests that transworld identity (TWI) canand should - be employed to analyse modal predications of objects that lack accidental intrinsic properties: God, it seems, lacks accidental intrinsic properties. Assuredly, Lewis would not have been happy to have accepted that modal claims about universals - if they exist - are to be analysed through CT; appealing to TWI-not CT - is appropriate in the case of universals. And so, if AT-claims appear unacceptable on CT, it is open for AT-GMRists to decide that CT is not appropriate for their AT-claims and opt for TWI instead. But, secondly, satisfaction of (2) is problematic for AT-GMRists. We wish to quantify unrestrictedly over God-like individuals (which includes quantifying over all worlds) — not just restrictedly over God-like individuals (which involves quantification only over the actual world) - and when we do so, AT-GMRists wish to see only one God-like individual, but instead they see a plurality of God-like individuals. Certainly, when we restrict our quantifier to the actual world, we do see one, unique God-like individual, so (1) is satisfied - but when we ask how many God-like individuals exist with our quantifiers open, we see that there exist infinitely many Godlike individuals. And, yes, there being an infinite plurality of God-like individuals, with only one in each world, renders God necessarily existent and necessarily unique; but, as we have seen, the AT-GMRist is not required to use CT to analyse (A)-kind-God's necessity. Thus, given that satisfaction of (2) is problematic - indeed, we end up with infinitely many God-like individuals - and given that the AT-GMRist need not employ CT, the AT-GMRist should therefore not employ CT to analyse (A)-kind-God's necessity.

But, there remains an additional plausible response to Sheehy and Davis's objection. There are two claims that are consistent with AT: (a) God is unsurpassable and (b) God is unmatchable. (a) broadly means that nothing is greater than God, since God is maximally great, and (b) broadly means that nothing is equal in greatness to God. Now,

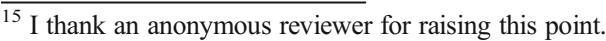


ATists are standardly taken as accepting the stronger claim, that is, that both (a) and (b) are true. But, perhaps, they need only hold the weaker claim, that is, that only (a) is true. Indeed, Hoffman and Rosenkrantz (2002: 87-88) briefly discuss this in relation to GMR: they hold that GMR is inconsistent with the stronger claim, but consistent with the weaker claim. This is because if we accept that CT is the correct way to analyse (A)kind-God's necessity, then there will exist as many (A)-kind-Gods as there are worlds, with each God being equal in greatness. Thus, the weaker claim is accounted for, but not the stronger.

Now, one may say here: 'Certainly, it is true that, historically, ATists have held the stronger claim, but ATists, historically, have not held that CT is the correct way to analyse (A)-kind-God's necessity. If CT is the correct way, then ATists will have to drop their stronger claim. And so, ATists, if they are to reject CT as the correct way to analyse (A)-kind-God's necessity, must argue that the stronger claim should be endorsed by ATists'. 16

Now, whilst I cannot do full justice to assessing this response-indeed, such a task would warrant a paper in its own right - there are several points I wish to make. After Sheehy's second objection, I supply a reason to think that ATists should hold the stronger claim that concerns the concept of maximal greatness, but here are some initial reasons.

Firstly, there are, it seems, scriptural reasons. Take, for instance, the following verses from the Book of Isaiah $^{17}$ :

Remember the former things of old: for I am God, and there is none else; I am God, and there is none like me. (Isaiah: 46:9)

To whom then will ye liken me, or shall I be equal? saith the Holy One. (Isaiah: 40:25)

To whom will ye liken me, and make me equal, and compare me, that we may be like? (Isaiah: 46:5)

These verses, I believe, give ATists scriptural reason to hold the stronger claim. Thus, the reason why ATists, historically, have held that God is unsurpassable and unmatchable seems - at least prima facie - scripturally justified, and so perhaps ATists' holding of the stronger claim is not merely historically accidental. Certainly, if ATGMRists thought that CT were the correct way to analyse (A)-kind-God's necessity, and so, on their theory, there exists a plurality of (A)-kind-God-counterparts, then ATGMRists - insofar as they let scripture guide them in their philosophical theologywould have to provide compelling hermeneutic reason why the above verses do not require, or perhaps do not heavily suggest, that there be only one God-like individual in all reality. Of course, ATists could claim that the above verses could be read from only the actual world's perspective; but, in any case, some serious hermeneutic work would need to be done.

Secondly, it does seem that if AT-GMR requires ATists to only make the weaker claim since CT is the correct way to analyse (A)-kind-God's necessity, then this counts as a relative cost of AT-GMR. Certainly, rival modal programmes - e.g. abstractionist

\footnotetext{
${ }^{16}$ I thank an anonymous reviewer for raising this point.

${ }^{17}$ I use the King James Bible for all Biblical translations.
} 
programmes - can accommodate the stronger claim. ${ }^{18}$ And so, for ATists who are at least uneasy in only accepting the weaker claim (that is, for those who think they at least might like to leave open the option of holding the stronger claim), there is good, prima facie reason to prefer certain rival theories (at least in this regard), if CT is the only way to analyse (A)-kind-God's necessity on AT-GMR. But, here, ATists' preference for rival theories will depend upon whether the cost of having to accept only the weaker claim is outweighed by the benefits wielded by AT-GMR.

And thirdly, there is the question of whether any AT-GMRist would wish to accept a CT reading of (A)-kind-God's necessity if it leads to AT-GMRists only being able to hold the weaker claim. Such a modal programme, I feel, would appeal to few ATists who harboured GMRist inclinations. ${ }^{19}$ This, however, is not to say that such a position is untenable-indeed, this is not a knockdown objection; it is only a check on the position's general attractiveness to the ATist who harboured GMRist inclinations. Such a position, I feel, will not receive much support from ATists. And so, even if the theory were a live option for ATists - which I do not think it is - such a theory will have little appeal.

And so, I argue that the above responses fail to satisfactorily circumvent or defuse Sheehy and Davis's objection; at best, the objection that there are many (A)-kind-Gods if we are to analyse (A)-kind-God's necessity through CT can be viewed as a benign consequence - but only if one is willing to accept that God is not unmatchable. SinceI should imagine - most ATists are not willing to accept this, the objection's consequence seems not so benign.

Now we can move on to Sheehy's (2006: 319-20) second objection. (A)-kind-God cannot be a creator of all reality — which is demanded by ATists ${ }^{20}$ — since individuals are world-bound and to be part of a world is to stand in a spatiotemporal and causal relation to parts of that world. On GMR, given that otherworldly individuals are just as real as the individuals in @, and given the world-bound nature of an (A)-kind-God, a single (A)-kind-God is unable to create all of reality, since creation is causal, and causal nexuses are confined to distinct worlds. That is, given their respective world-bound natures, @-God only creates @, and w-God only creates w. Yes, from the perspective of @, @-God will be the creator of reality; but from the logical space-perspective, @-God will only be creator of a small patch of reality — when we say 'all of reality' our quantifiers include all logical space, that is, all worlds.

However, as Vance $(2016 ; 570, \mathrm{n} 5)$ briefly notes, ATists may respond: the true (A)kind-God, say @-God, is, somehow, responsible for all reality, since the otherworldlyGods are creatively inert 'imposters'. Vance highlights a difficulty with this response: Since@-God's counterparts are creatively inert imposters, they thus seem to fail to qualify for the type of God-like individual that ATists require. If that is so, the creator God, @-God, is rendered a contingent and not a necessary being. Now, Vance seems generally correct here: the problem is not that God's creation of worlds will be

\footnotetext{
${ }^{18}$ See Hoffman and Rosenkrantz (2002: 88) for more on this point of abstractionism accommodating the stronger claim of God.

${ }^{19}$ Indeed, perhaps it is unsurprising that Almeida, one of the chief supporters of AT-GMR, does not invoke CT to analyse God's necessity.

${ }^{20}$ Indeed, all classical theists — not just of the ATist stripe - affirm God's being the creator of all reality. Thus, anywhere in this article where discussion of God's being the creator of all reality crops up, such discussion will interest all classical theists.
} 
contingent - indeed, that claim coheres with AT's contention that God's creation of the world is contingent ${ }^{21}$ _ but rather, positing that there exits only one true God, @-God, makes@-God's existence (and not His being a creator) contingent. But, I argue, a more troublesome problem exists ${ }^{22}$ : Since world-creation is causal, were @-God the creator of all reality (i.e. the total set of worlds), @-God would be causally connected to all worlds; and so all worlds will thence be causally connected to each other through being causally connected to @-God. But, since GMR-worlds are causally isolated individuals, this implies that there exists only one world, and thereby total modal collapse ensues. ${ }^{23}$ If modal collapse ensues, this does not mean that AT-GMR is false - in fact, such a modal programme simply becomes trivially true: AT-GMR will have only one possible world, and this will be concrete. But, it seems, such a modal programme will not be attractive to most AT-GMRists - unless most AT-GMRists have necessitarian views on modality.

Now, one may ask here: Why think that AT is committed to the view that one maximally great being created all concreta (other than Himself) ${ }^{24}$ In essence, my response, I think, is already given above: that is, there is reason to think that ATists should hold the stronger claim-i.e. that God is unsurpassable and unmatchable. If I am right there, I should be right here. But, there is also reason to hold that the notion that no being ought to be able to create as much as or more than one maximally great being spills out of the concept of maximal greatness. Suppose, for example, we are told that a maximally great being, @-God, only created and sustains @, and we are also told that there exists a plenitude of other worlds not created and sustained by @-God. Now, the property of creating things and the property of sustaining things seem — at least — to be great-making properties. We can reasonably ask then: how can a maximally great being be maximally great if it only created and sustains a tiny patch of reality? If the respective properties of creating things and sustaining things are great-making properties, it seems that for @-God to be truly maximally great, He should create and sustain all reality (that is, all worlds) — otherwise, He seems to fall short of maximal greatness. Of course, if CT is the correct way to analyse God's necessity, then ATists must accept this result - but, as we have seen, AT-GMRists need not accept CT; they can use TWI. Thus, if TWI allows one to say that one God created and sustains all reality, and (at least the ability for) creating and sustaining all reality is necessary for a being's maximal greatness, then AT-GMRists have reason to accept TWI as the correct analysis of God's necessity. So, there is reason to think that the stronger claim spills out of the concept of maximal greatness, which gives motivation to reject $\mathrm{CT}$.

A response, here, might be: one (A)-kind-God, perhaps @-God, could still be the ground of all reality, even if $\mathrm{He}$ is not the creator and sustainer of all reality. This suggestion, I think, will not work: it is odd to think that, out of a plurality of (A)-kindGods, there is one that is the ground of all worlds - even those worlds that are causally isolated from Him, and thus are neither created nor sustained by Him. My intuition is that if such an (A)-kind-God were removed from existence (which I appreciate is a

\footnotetext{
${ }^{21}$ There may be a problem here, however: since ATists hold that it is contingent that God create, there must exist a world in which there exists nothing - but, on GMR, there are no empty-worlds. So, on GMR, it appears (contra AT) that God's creation of worlds cannot be contingent.

${ }^{22}$ Vance $(2016 ; 570, \mathrm{n} 5)$ hints at this problem.

${ }^{23}$ I later explain why this might be taken as being problematic.

${ }^{24}$ I thank an anonymous reviewer for offering both this response and the one below.
} 
counterpossible, but the conceptual point still runs), the worlds that were created and sustained by the other (A)-kind-Gods would still exist. But, at any rate, we incur a similar problem to one incurred by the suggestion that one, true creator God exists: that is, if we take this line of response, we end up with a contingent (A)-kind-God. If one (A)-kind-God had attributes relevant to maximal greatness that the other (A)-kind-Gods lacked, the other 'Gods' would not seem appropriate counterparts; grounding all reality seems a relevant attribute to maximal greatness; so, such a grounding God seems to lack counterparts in all worlds, and so such a God is contingent. Thus, for the sake of having one grounding God, we end up with a contingent God.

Now, I have raised the idea that AT-GMRists can drop CT and opt for TWI insteadthis is Cameron's (2009: 98-100) general objection to Sheehy's strategy. Sheehy thinks that AT-GMR should use CT, by appealing to NEC-G, to analyse God's necessary existence. But, GMR appears to possess the machinery to avoid using CT, and, instead, use TWI. Cameron notes, as we noted above: for any individual that fails to instantiate accidental intrinsic properties (i.e. individuals that only instantiate essential intrinsic properties), GMR can use TWI. So, if AT's God is like this, GMRists can appeal to TWI to account for God's necessary existence. But, before I explore Cameron's objection, I shall initially sketch TWI's thesis.

Roughly, in asserting that individuals $x$ and $y$ are transworld identical, one asserts: there exists (at least) two distinct worlds, $w$ and $u$, whereby $x$ exists wholly in $w$ and $y$ exists wholly in $u$, and there is identity between $x$ and $y$; viz., one asserts that, numerically, one and the same individual exists in distinct possible worlds (Mackie and Jago 2013). Here is TWI's thesis ${ }^{25}$ :

TWI: an individual, $x$, exists and worlds, $w$ and $u$, exist and $w \neq u$, and $x$ is wholly a part of $w$ and $x$ is wholly a part of $u$.

So: for TWI-AT-GMRists, numerically one and the same God exists as an individual-part wholly in $w$ and wholly in $u$, where $w$ and $u$ are distinct worlds.

Now on to Cameron's objection. Cameron (2009: 99-100) notes: CT is not motivated by the need to represent, de re, individuals which have all their intrinsic properties essentially, in contrast to accidentally; AT's God, plausibly, is such an individual. If God is intrinsically $F$ in @, then, on AT, at all worlds He is intrinsically $F$. That is, for AT, the following axiom seems true (where $g=\mathrm{God}$, and $F=$ an intrinsic property): ' $F g \supset F g$ '. If ' $F g \supset F g$ ' is true, then, on GMR, no difficulty should arise in claiming that numerically one and the same God exists in all worlds, and, thereby, is a necessary existent. On Cameron's proposal, ATists avoid Sheehy's objection pertaining to God's uniqueness, and thereby avoid having recourse to problematically contending that@-God is the true, creator God, or @-God is the true, grounding God. Thus, (contra Sheehy) GMR possesses the resources to account for God's necessary existence, whilst retaining His uniqueness, through using TWI-not CT.

Cameron's proposal, however, fails for three reasons, I argue.

The first reason, originally raised by Sheehy (2009: 103-4), is that Cameron's proposal commits AT-GMRists to a revisionary account of the indexical term 'actual' and its cognate-terms. On Cameron's proposal, given God's (A)-kind ontology, God is

\footnotetext{
${ }^{25}$ See Divers (2002: 259) for more precise formulations.
} 
part of all worlds - thus, God is spatiotemporally connected to a world in which I reside. But, recall: if any two (or more) individuals are part of the same world by being spatiotemporally connected, they are world-mates. Thus: should I regard God as my @ world-mate? GMR says yes. But, then, GMR's indexical gloss of the term 'actual' is distorted. When employing the term 'actual' in world, $w$, one quantifies only over $w$; when God, however, employs the term 'actual', through being in all worlds, He quantifies over all worlds. That is, since God exists in all worlds, all worlds, to Him, are actual. So, when my world-mate, God, and I employ the term 'actual' our referents are distinct; the identity-type of the speaker is now of import for the quantificational scope of the term. This jars with GMR's prescribed interpretation: world-mates' usage of 'actual' ought to have the same quantificational scope.

Sheehy is correct, here, I believe: if God and I agree on a single usage of 'actual', the appropriate quantificational restrictions are forsworn; if I follow God's usage of 'actual', I quantify over too much, and if He follows my usage, He quantifies over too little. But, Sheehy's objection, although challenging, is not, however, devastating. The indexicality of 'actual' is not as central to GMR, as, say, the individuation conditions for worlds; thus, perhaps revisions or restrictions on its usage are acceptable, particularly if AT-GMRists can retain both God's necessary existence and His uniqueness. So, my second reason, which also concerns world-mateship, is required.

Now, if $x$ and $y$ are world-mates, then $x$ and $y$ are spatiotemporally connected. Moreover, world-mateship is transitive: if $x$ is a world-mate of $y$, and $y$ is a world-mate of $z$, then $x$ is a world-mate of $z$-this is because world-mateship is grounded in the spatiotemporal relation, which is, itself, transitive. But, here, I argue, Cameron's proposal fails: God, by existing in all worlds, is my @-world-mate, but is also otherworldly-Bill's w-world-mate. Now, if I am God's world-mate, and God is Bill's world-mate, then, by transitivity of world-mateship, I am also Bill's world-mate, despite my being wholly in @ and his being wholly in $w$. The problem is thus: since world-mateship is grounded in the spatiotemporal relation, and since I am, through God's existing in both @ and w, Bill's world-mate, I am spatiotemporally related to otherworldly-Bill. But, since worlds are spatiotemporally isolated individuals, and since Bill's w and my @ are, by God's existing in both, spatiotemporally connected, $w$ and @ are one and the same world. Indeed, since God exists in all worlds, by transitivity of world-mateship, I am a world-mate of all individuals in all worlds; thus, all 'worlds' are spatiotemporally linked, and so only one, multiverse-world exists. Therefore: again, total modal collapse ensues. Moreover, if I am correct here, worldmateship becomes trivial; to be a world-mate of anything is simply to exist.

The third reason (noted by Vance (2016: 567-8)) is linked to my second and to my objection to positing @-God as the one true creator: If God exists in all worlds as a part, and is the creator of all worlds, and creation involves causation, then all worlds are causally connected. But, GMR-worlds are causally isolated individuals. Thus: all 'worlds', through having a plurality-of-worlds-creator God wholly existing in them as a part, are numerically identical. Total modal collapse, again, ensues.

Now, I have mentioned modal collapse a few times; but why might it be considered problematic? Well, modal collapse renders more propositions necessary than is (typically thought) acceptable: on GMR, if there existed one world only, otherworldly counterparts would not exist. So, the proposition that, say, $<\mathrm{I}$ am in Oxford $>$ would come out as necessary, since I would have no otherworldly counterparts who are in 
otherworldly counterpart cities to render that proposition contingent. So, whilst modal collapse would render God's existence necessary, this comes at the price of every individual's existence being necessary. Now, I do not argue that modal collapse is not acceptable, but nor do I say it is acceptable; although I suspect most will find it unacceptable, I leave it up to others to decide.

Kraay (2011), however, is one who bucks the (suspected) trend. ${ }^{26}$ In a multiverse (a web of connected universes), there exists a vast plurality of universes that differ in significant ways. The hope, for Kraay, is that these differences in the multiverse's universes can be used to provide a serviceable theory of modality. ${ }^{27}$ Thus, ATists could use Kraay's suggestion and individuate worlds in terms of universes, as parts of the multiverse, and not in terms of spatiotemporally and causally isolated individuals. So, despite universes' causal overlap through God, they could be regarded as distinct enough to function as worlds. ${ }^{28}$

Kraay's response, I argue, in addition to not qualifying as GMR (since it rejects a key individuation condition of worlds for GMR (viz., causal isolation)), seems ad hoc: certainly, the Kraayist is committed to explaining why worlds should be causally isolated except when causal overlap is through God, in a way that is not merely preserving AT's (A)-kind-God on a concretist possible worlds account. I have doubts if this can be achieved. But, at any rate, as stated, Kraay's proposal is not GMRfriendly, and since GMR is under scrutiny here, and since I leave it open as to whether modal collapse is unacceptable, I shall bypass discussion of the proposal.

Now, at this point, one may be tempted to say: God is concrete, but exists outside worlds. There are two problems here. Firstly, if a concrete God exists outside worlds, then - at best - GMR fails to provide a model to account for all necessities, and - at worst - GMR renders God impossible (and so not-necessary), since all possible individuals exist in worlds. And secondly, if God is causal, as He should be, He cannot exist outside worlds, as causation is in worlds - so, God must be causally inert if He exists outside worlds. So, the first problem demonstrates the proposal's incompatibility with GMR and the second demonstrates the proposal's incompatibility with AT.

And so, if God is (A)-kind on AT-GMR, AT-GMRists must choose one of two results: if CT is used - amongst other things - there exists many (A)-kind-Gods, and if TWI is used - amongst other things - modal collapse ensues. I suspect that acceptance of modal collapse will not appeal to many AT-GMRists, and I suspect that there being a plurality of Gods will likewise seem unpalatable. But I leave it up to (A)-kind-God-ATGMRists to decide which option they should take.

\section{(B)-Kind-God}

So, let us now assume that God is (B)-kind.

Recall: (B)-kind individuals exist partly in worlds, through having parts that wholly exist in those worlds-i.e. they are cross-world individuals, comprised of

\footnotetext{
${ }^{26}$ Although Kraay does not focus on AT and GMR, his suggestion is applicable here.

${ }^{27}$ Another way to avoid modal collapse through causal overlap is to deny that causation is transitive; that appears not only ad hoc but profoundly revisionary.

${ }^{28}$ Lewis (1986: 209) briefly mentions such a programme.
} 
two or more (A)-kind individuals (e.g. the mereological summation of (A)-kindcounterparts). So, (B)-kind-God is one cross-world-individual: He is the summation of all (A)-kind-God-counterparts that, individually, exist wholly in worlds. However, (B)-kind-God is, firstly, not compatible with AT-GMR, and, secondly, leads to modal collapse.

Now, Vance (2016: 563) argues: (B)-kind-God is not wholly located in any world because He only partially exists in each world-but, if (B)-kind-God is not wholly located in, say, @, then He is not omnipresent in @ (and this, extends to all worlds). This threatens God's omnipresence. But, Vance errs here, I believe: God would still be omnipresent in @ by having an @-part that bore the relations to all other parts of @ that classically suffice for omnipresence in @ (i.e. by having a part of God bore suitable causal (here, most likely: sustaining) and/or epistemic relations to all parts of @); if every world-part of God did that, God would thereby be transworld-omnipresent. ${ }^{29}$ It would not, as perhaps Vance worries, be 'whole in the whole omnipresence', but a whole can be present at a place through having a part there, and being present at every place just is omnipresence-(B)-kind-God is just like that. Vance's second objection, however, is more troubling: God is mereologically simple, and is thereby indivisible; but, if God is (B)-kind, then, through being composed of proper parts, He is divisible, and is, thus, not simple. ${ }^{30}$ Vance is correct here, and this is a serious problem for AT-GMRists sympathetic to (B)-kind-God. ${ }^{31}$

ATists might contend, however: (B)-kind-God remains, in a sense, one God. So, perhaps, despite being incompatible with divine simplicity, (B)-kind-God is preferable to (A)-kind-God-at least (B)-kind-God satisfies monotheism. Now, although this claim is true, it is nevertheless problematic. Indeed, Vance (2016: 563) claims: God's oneness, in this manner, is scarcely natural; to speak of (B)kind-God's being unified is no less (and arguably more) bizarre than to speak of the unification of an individual composed of, say, Venus and Mars; both complex individuals are diffuse, scarcely appropriately connected individuals. ${ }^{32}$ And even if ATists accept this oddity, Vance thinks that God will not be unified in a theistically important way, e.g. His being a unified consciousness. Now, Vance errs on this last point, I believe: firstly, the Trinity might present a counterexample here, but secondly, God would be a unified consciousness if His parts were, say,

\footnotetext{
${ }^{29}$ This form of omnipresence is called derivative omnipresence. It is distinguished from fundamental omnipresence, which requires that an object be present at a spatial region in the same way that my laptop is present at a spatial region. For recent discussions of omnipresence, see Hudson (2014), Inman (2017) and Cowling and Cray (2017).

${ }^{30}$ An anonymous reviewer thinks that the way that (B)-kind-God is not simple might not concern a classical theist: indeed, there is no threat of 'decomposition' or 'dissolution'. I think it would, however, concern the classical theist: God should not depend upon parts in the way that composite objects do-God exists a se.

${ }^{31}$ Another possible way to block Vance here is to insist that (B)-kind-God is a transworld, extended simple. For work on extended simples, see McDaniel (2007).

32 One may argue here: worlds are considered individuals, and so an individual composed of Venus and Mars does seem possible - namely, a world in which both Venus and Mars exist. I grant this. However, what unifies worlds is spatiotemporal and causal relatedness. (B)-kind-God cannot be unified by these relations: (B)-kindGod cannot be unified by spatiotemporal relatedness, as worlds are spatiotemporally isolated, and so (B)-kindGod's parts should be spatiotemporally isolated, and, as we will see below, (B)-kind-God cannot be unified by casual relatedness, since this would incur total modal collapse.
} 
causally connected across-worlds, which, if He were a single entity, would be so. ${ }^{33}$ But, I think generally Vance is correct: one may initially think, contra Vance, that (B)-kind-God's unity is as natural as the unity of a natural class, given the likeness of His parts-but, (B)-kind-God is not a natural class, but an individual. Indeed, thinking that (B)-kind-God's unity is as natural as a natural class's unity highlights that such a scattered individual seems more like a set, insofar as the member-set relation should apply to such entities, and not the part-whole relation. $^{34}$

Vance (2016: 563) additionally argues that a (B)-kind-God is incompatible with GMR since Lewis (1983: 40) claims that such individuals are impossible individuals; to be a possible individual is to exist wholly in a world-(B)-kind-God does not. Now, there is room for AT-GMRists to resist Vance here: the following passage from Lewis (1986) jars with Vance's argument:

I do not deny the existence of transworld individuals, and yet there is a sense in which I say that they cannot possibly exist. As should be expected, the sense in question involves restricted quantification. ... It is possible for something to exist iff it is possible for the whole of it to exist. That is, iff there is a world at which the whole of it exists. That is, iff there is a world such that, quantifying only over parts of that world, the whole of it exists. That is, iff the whole of it is among the parts of some world. That is, iff it is part of some world - and hence not a transworld individual. Parts of worlds are possible individuals; transworld individuals are therefore impossible individuals.

To call the transworld individuals 'impossible' in this sense is not an argument for ignoring them - that comes later. It is only a terminological stipulation. If we thought they should not be ignored... it would be appropriate and easy to give 'possible individual' a more inclusive sense. We could say that an individual exists at a world iff, quantifying only over parts of that world, some part of that individual exists - that way, the transworld individuals would count as possible. ${ }^{35}$ (Lewis 1986: 211)

Indeed, (contra Vance) Lewis thinks that if we are not convinced by his reasons for why we should not endorse (B)-kind individuals, then we can render such individuals possible by employing the biconditional: $x$ exists at world, $w \leftrightarrow$ when quantifying only over parts of $w$, some part of $x$ exists. AT-GMRists may think that there are good reasons to accept at least one (B)-kind individual-i.e. (B)-kind-God-and so they will think that there are good reasons to affirm the above biconditional.

I argue, however, that AT-GMRists should deny the possibility of (B)-kind-God, and thus should reject the above biconditional (in the absence of other reasons to affirm it). The reason is that, on the assumption that God is (B)-kind, and a causally efficacious part of Him exists in all worlds, we end up, again, with modal collapse. Here is my argument: If a causal part of (B)-kind-God is part of $w$ and a causal part of (B)-kindGod is part of @, then@ is causally connected to $w$ through @'s being causally

\footnotetext{
33 This would, however, lead to modal collapse again. I develop this response below.

${ }^{34}$ I subsequently explore Cameron's suggestion that God is ontologically like pure sets.

${ }^{35}$ I thank one anonymous reviewer for drawing this passage in Lewis (1986) to my attention, and another for inspiring me to write my response below.
} 
connected to a part of (B)-kind-God who has a part that is causally connected to $w$; if worlds are causally connected, those worlds are one and the same world; so, @ and w are one and the same world. This result should apply to all worlds: if (B)-kind-God has a causal part in all worlds, and His parts are unified, then all worlds become one. Thus, the AT-GMRist who wishes to deny the claim that (B)-kind-God is impossible incurs total modal collapse.

Perhaps (B)-kind-God-AT-GMRists will demur here: they may say that parts of (B)kind-God are causally isolated - no part of (B)-kind-God is causally connected to any other part of (B)-kind-God-and so there are no transitivity of causation problems that lead to modal collapse. This response, however, merely puts my point above in stark relief: how is such an individual unified? The need for the (B)-kind-God AT-GMRist to provide an account of this becomes even more exigent when causal (along with spatiotemporal) connectedness of its parts is not an option.

And so, (B)-kind-God is not an easy option for AT-GMRists to take: God is not simple and is scarcely unified in the way that individuals should be, and if $\mathrm{He}$ is causal and unified, then modal collapse ensues.

\section{(C)-Kind-God}

So, let us finally assume that God is (C)-kind.

Recall: (C)-kind-beings exist from a world's perspective, through being members of the most unrestricted domain that is considered, generally, suitable for evaluating the truth values of quantifications at worlds-i.e. non-individuals (e.g. pure sets...). Cameron (2009: 97) and Almeida (2017) suggest taking God as ontologically like abstract pure sets. This proposal, they contend, would render God's existence necessary, since pure sets, from all worlds' perspectives, exist 'at' all worlds. I argue, however: the Cameron-Almeida proposal fails.

Now, before I explain why the proposal fails, let us examine two plausible, but defective, objections. The first, presented by Vance (2016: 565), highlights that ATists claim of God that, in the world He is wholly, rather than partially, present; thus, the partwhole relation should apply. However, (C)-kind-God is ontologically like pure sets, so He cannot be wholly present in the world, since the part-whole relation is inapplicable to anything save individuals, which exist in, rather than at, worlds. And, as Vance notes, Lewis (1983: 40) claims: '... I take it that the part-whole relation applies to individuals, not sets. Then no set is in any world in the sense of being part of it'. Here, I think, Vance errs; indeed, he misapprehends (or at least too literally understands) the proposal. Cameron and Almeida claim that (C)-kind-God has the same status as pure sets qua being abstract; this is not to say that (C)-kind-God is exactly like pure sets in every respect - if this were so, the proposal would simply be a non-starter. But, the Cameron-Almeida proposal would, however, install a novel entity-kind into GMR - thus the second objection: Sheehy (2009: 103) argues that positing a (C)-kind-God violates a motivational element of GMR: ontological, qualitative parsimony. Ontologically, GMR may be quantitatively profligate, but is qualitatively economical: on GMR, there exists, only, (abstract) sets and (concrete) individuals. With individuals and iterative set-theory, only, GMR wields considerable ontological explanatory power, e.g. propositions are sets of worlds. Thus, when positing 
(C)-kind-God, GMR demands that its being posited is motivated by its being explanatorily fruitful. Sheehy maintains: ATists' antecedent commitment to (C)-kind-God's necessary existence determines that this entity-type is included in their GMR-ontological-primitives inventory, which, when juxtaposed with GMR's motivations for positing sets and individuals appears ad hoc. I argue: it need not be.

Positing a (C)-kind-God may, in fact, provide many ontological explanations, e.g. if one were realist about moral facts, (C)-kind-God may ontologically ground such otherwise mysterious facts. ${ }^{36}$ Moreover, positing a creator-(C)-kind-God may provide GMR with an explanation for how and why an infinite plurality of worlds exists. Indeed, one may ask: how and why is it that such modality-grounding worlds exist? I hypothesise: AT may possess the resources to provide GMR with a theistically grounded answer: perhaps God's nature is such that He create ex nihilo or perhaps He chooses to do so. Thus, Sheehy's contention appears more challenge than objection: ATists could avoid Sheehyist ad hoc-cries by underscoring the ontological explanatory power afforded by (C)-kind-God, and thus adding Him to GMR's ontologicalinventory is perhaps suitably motivated.

But here difficulty lies. Indeed, Vance (2016: 565-6) notes two connected problems: ATists hold that God, although being non-spatiotemporal, is spatiotemporally worldrelated, and is causally efficacious. However, since God fails to exist in worlds, He fails to be spatiotemporally connected to worlds, and since abstracta are non-causal, ${ }^{37}$ (C)kind-God could not create worlds (so, ATists are not able to rebut Sheehy's objection in the way I have outlined above).

Now, there is a way to rebut Vance; but I believe it fails. ATists could insist on a reverse form of abstracta-creationism: It is not that spatiotemporal individuals create abstracta, but an abstractum (here, (C)-kind-God) creates spatiotemporal individuals. ${ }^{38}$ This manoeuvre (contra Vance) would thus render God causal and spatiotemporally world-connected.

Immediately, such an entity appears rather sui generis (and then perhaps the proposal is more ad hoc than Sheehy first thought). But, ATists may point out: since some do not object to creationism in the form of (A)-kind-God creating or at least sustaining abstracta (given His aseity), why should a concreta-creating-(C)-kind-God seem so outlandish? After all, God is a sui generis entity anyway. This is perhaps fair. But I have a more devastating objection. Insisting on (C)-kind-God's causal efficacy, whilst cohering with AT, makes GMR trivially true: if (C)-kind-God is spatiotemporally connected to, and the creator of (and thus causally connected to), all worlds, then, again, all worlds become one- that is, modal collapse ensues. So, the CameronAlmeida proposal is rather precariously positioned. (C)-kind-God, on a conventional understanding of abstracta, is neither spatiotemporally nor causally related to worldsthis violates AT. But, (C)-kind-God, on an unconventional understanding of abstracta, by being spatiotemporally and causally related to worlds generates modal collapsethis makes GMR trivially true. So, I argue: it does not seem that it is even in Cameron and Almeida's interests to rescue (C)-kind-God from the above objections.

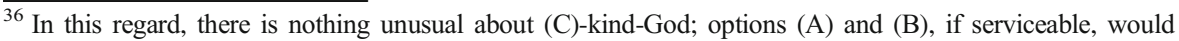
deliver the same result — but those options have already been rejected, or, at any rate, I have already suggested that they are quite costly.

${ }^{37}$ See Rosen (2017) for the causal inefficacy of abstracta.

${ }^{38}$ See Kripke (2013) for abstracta-creationism.
} 


\section{Conclusion}

I have exhausted the ontological options for God on AT-GMR, and have found all wanting - or, at least, I have found all rather costly. Regardless of whether we construe God as concrete or abstract, His necessity delivers problems for AT-GMR. Almeida's ((Almeida 2011), 18, n19) claim: '[GMR] offers a way to say everything we have wanted to say about the necessary existence of [AT]'s God', is thereby false - unless all we wanted to say was that, on GMR, it is false that God is necessary, or that modal collapse, along with other costs, is not (too) pricey.

Moreover, if what I have said in this paper is correct, both the ATist and the GMRist will be equipped with new arguments. For the GMRist, he will have an argument against the existence of God, and for the ATist, he will have an argument against the truth of GMR. Indeed, if there are good arguments to support AT, and I am correct that AT and GMR are incompatible or their conjunction is objectionable (through, amongst other things, modal collapse's being objectionable (at least to some)), then the ATist can employ these arguments to demonstrate the falsity of GMR; and, if there are good arguments to support GMR, and I am correct that GMR and AT are incompatible or their conjunction is objectionable (through, amongst other things, modal collapse's being objectionable (at least to some)), then the GMRist can employ these arguments to demonstrate the falsity of AT. Almeida and others who think that there are good, compelling arguments to support both AT and that there are good, compelling arguments to support GMR, should therefore suspend their judgement over both the truth of AT and the truth of GMR.

\section{Compliance with Ethical Standards}

Conflict of Interest The author declares that there is no conflict of interest.

Open Access This article is distributed under the terms of the Creative Commons Attribution 4.0 International License (http://creativecommons.org/licenses/by/4.0/), which permits unrestricted use, distribution, and reproduction in any medium, provided you give appropriate credit to the original author(s) and the source, provide a link to the Creative Commons license, and indicate if changes were made.

\section{References}

Almeida, M. J. (2008). The metaphysics of perfect beings. New York: Routledge.

Almeida, M. J. (2011). Theistic modal realism? In J. L. Kvanvig (Ed.), Oxford studies in philosophy of religion volume 3. Oxford: Oxford University Press.

Almeida, M. J. (2017). Theistic modal realism II: Theoretical benefits. Philosophy Compass, 12(7), e12418. https://doi.org/10.1111/phc3.12418.

Cameron, R. (2009). God exists at every (modal realist) world: Response to Sheehy. Religious Studies, 45, 95100.

Cowling, S., \& Cray, W. D. (2017). How to be omnipresent. American Philosophical Quarterly, 54(3), 223234.

Davis, R. (2008). God and modal concretism. Philosophia Christi, 10(1), 57-74.

Davis, R. (2009). Oppy and modal theistic proofs. Philosophia Christi, 11(2), 437-444.

Divers, J. (2002). Possible worlds. London: Routledge.

Hoffman, J., \& Rosenkrantz, G. S. (2002). The divine attributes. Oxford: Blackwell. 
Hudson, H. (2014). The fall and hypertime. Oxford: Oxford University Press.

Inman, R. D. (2017). Omnipresence and the location of the immaterial. In J. Kvanvig (Ed.), Oxford studies in the philosophy of religion, VIII. Oxford: Oxford University Press.

Kraay, K. J. (2011). Theism and modal collapse. American Philosophical Quarterly, 48, 361-372.

Kripke, S. (1980). Naming and necessity. Oxford: Oxford University Press.

Kripke, S. (2013). Reference and existence. Oxford: Oxford University Press.

Leftow, B. (2012). God and necessity. Oxford: Oxford University Press.

Lewis, D. K. (1968). Counterpart theory and quantified modal logic. The Journal of Philosophy, 65, 113-126 Reprinted In: M, Loux, ed., 1979. The Possible and the Actual. Ithaca, NY: Cornell University Press.

Lewis, D. K. (1983). Postscripts to "counterpart theory and quantified modal logic". In Philosophical papers volume I (pp. 40-46). Oxford: Oxford University Press.

Lewis, D. K. (1986). On the plurality of worlds. Oxford: Blackwell.

Mackie, P. and Jago, M. (2013). Transworld identity. [Online] The Stanford Encylopedia of Philosophy. E. N. Zalta, ed. Available at: <https://plato.stanford.edu/entries/identity-transworld > [Accessed 10 February 2018].

McDaniel, K. (2007). Extended simples. Philosophical Studies, 133(1), 131-141.

Menzel C. (2016). Possible worlds. [Online] The Stanford Encylopedia of Philosophy. E. N. Zalta, ed. Available at: <http://plato.stanford.edu/archives/sum2015/entries/possible-worlds/> [Accessed 8 February 2018].

Oppy, G. (1993). Modal theistic arguments. Sophia, 32(2), 17-24.

Oppy, G. (2009). Reply to Richard Davis. Philosophia Christi, 11(2), 423-436.

Plantinga, A. (1974). The nature of necessity. Oxford: The Clarendon Press.

Plantinga, A. (1985). Self-profile. In J. E. Tomberlin \& P. van Inwagen (Eds.), Alvin Plantinga (pp. 3-100). Dordrecht: D. Reidel Publishing Company.

Rosen G. (2017). Abstract objects. [Online] The Stanford Encylopedia of Philosophy. E. N. Zalta ed. Available at: <https://plato.stanford.edu/entries/abstract-objects/> [Accessed: 5 September 2017].

Sheehy, P. (2006). Theism and modal realism. Religious Studies, 42, 315-328.

Sheehy, P. (2009). Reply to Cameron. Religious Studies, 45, 101-104.

Steinhart, E. (2013). On the plurality of gods. Religious Studies, 49, 289-312.

Vance, C. (2016). Classical theism and modal realism are incompatible. Religious Studies, 52, 561-572. 